\title{
Understanding the Role of Nanoparticle Synthesis on Their
}

\section{Underlying Electrocatalytic Activity}

Han-Pu Liang, ${ }^{\dagger *}$ Timothy G. J. Jones, ${ }^{\dagger}$ Nathan S. Lawrence, ${ }^{\dagger} *$ Li Jiang $^{\ddagger}$ and Jonathan S. Barnard ${ }^{\S}$

\footnotetext{
${ }^{\dagger}$ Schlumberger Cambridge Research, High Cross, Madingley Road, Cambridge, CB3 0EL, UK, ${ }^{\star}$ Schlumberger-Doll Research, 1 Hampshire Street, Cambridge, Massachusetts 02139,

${ }^{\S}$ Department of Materials Science and Metallurgy, University of Cambridge, Pembroke Street, Cambridge CB2 3QZ, UK
}

RECEIVED DATE (to be automatically inserted after your manuscript is accepted if required according to the journal that you are submitting paper to)

* To whom correspondence should be addressed. Fax: +44 1223467004

E-mail: hliang@cambridge.oilfield.slb.com nlawrenc@ cambridge.oilfield.slb.com 


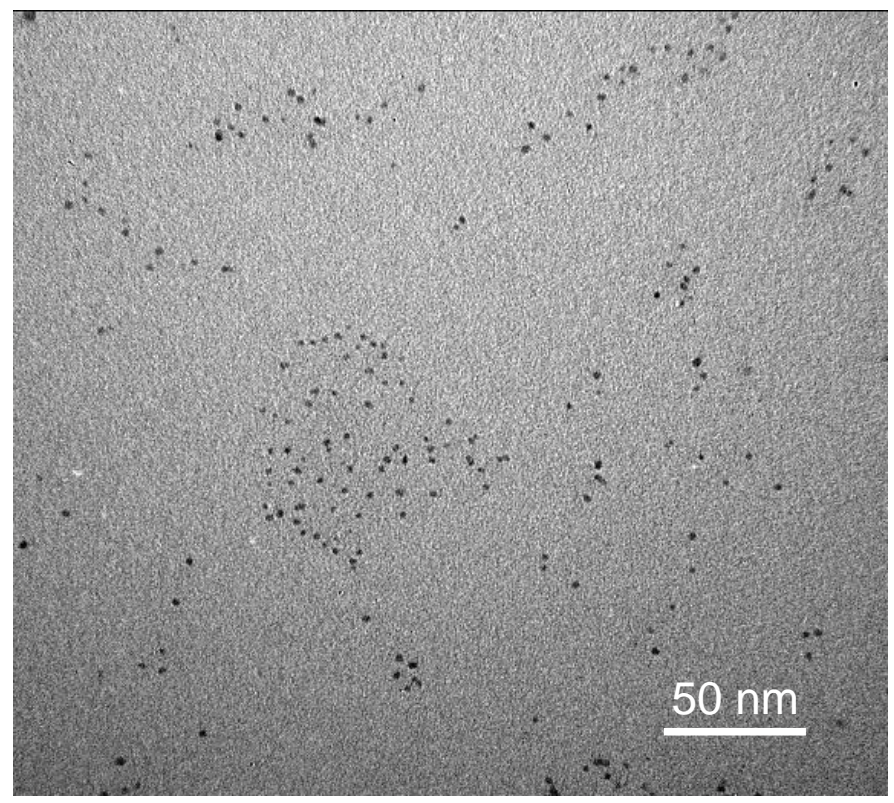

Figure S1: Typical TEM image of Pt nanoparticles using PVP as stabling agent

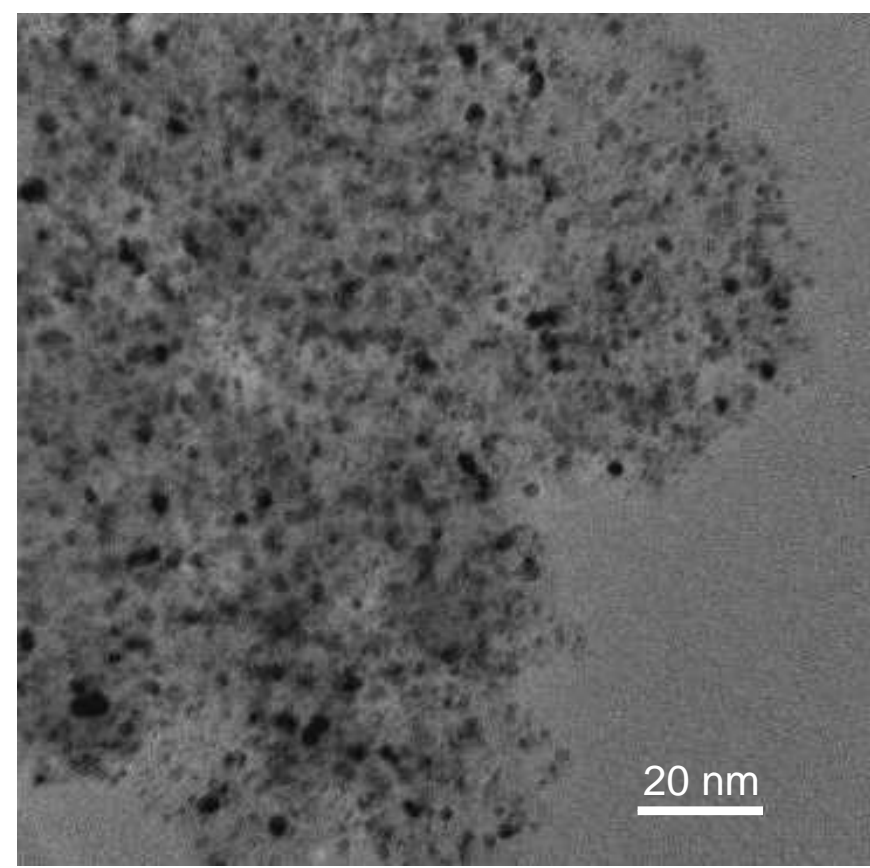

Figure S2: Typical TEM image of unprotected Pt nanoparticles 


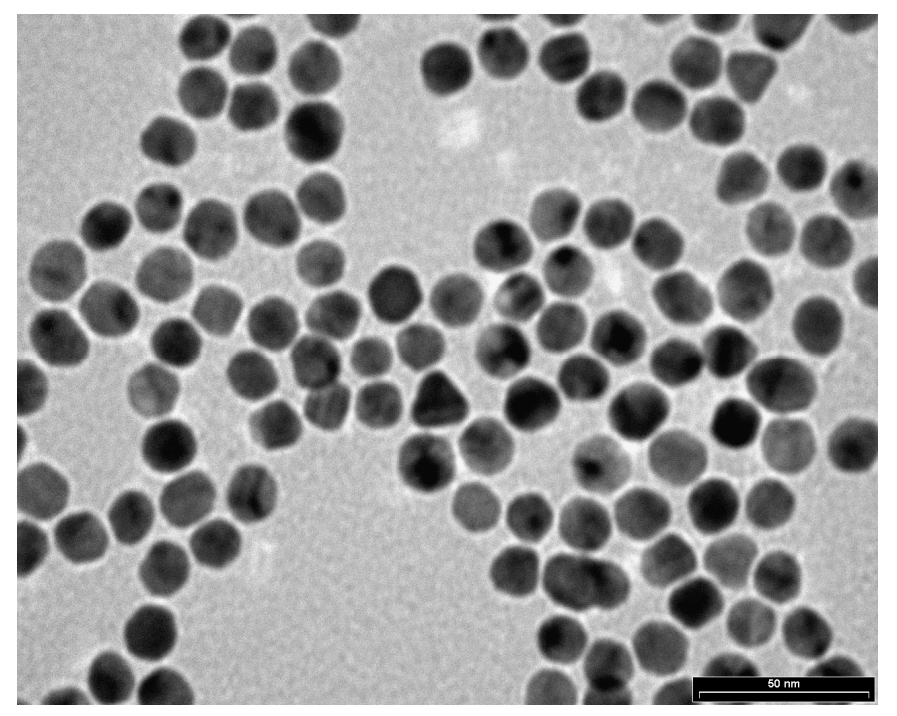

Figure S3: Typical TEM image of Au nanoparticles.

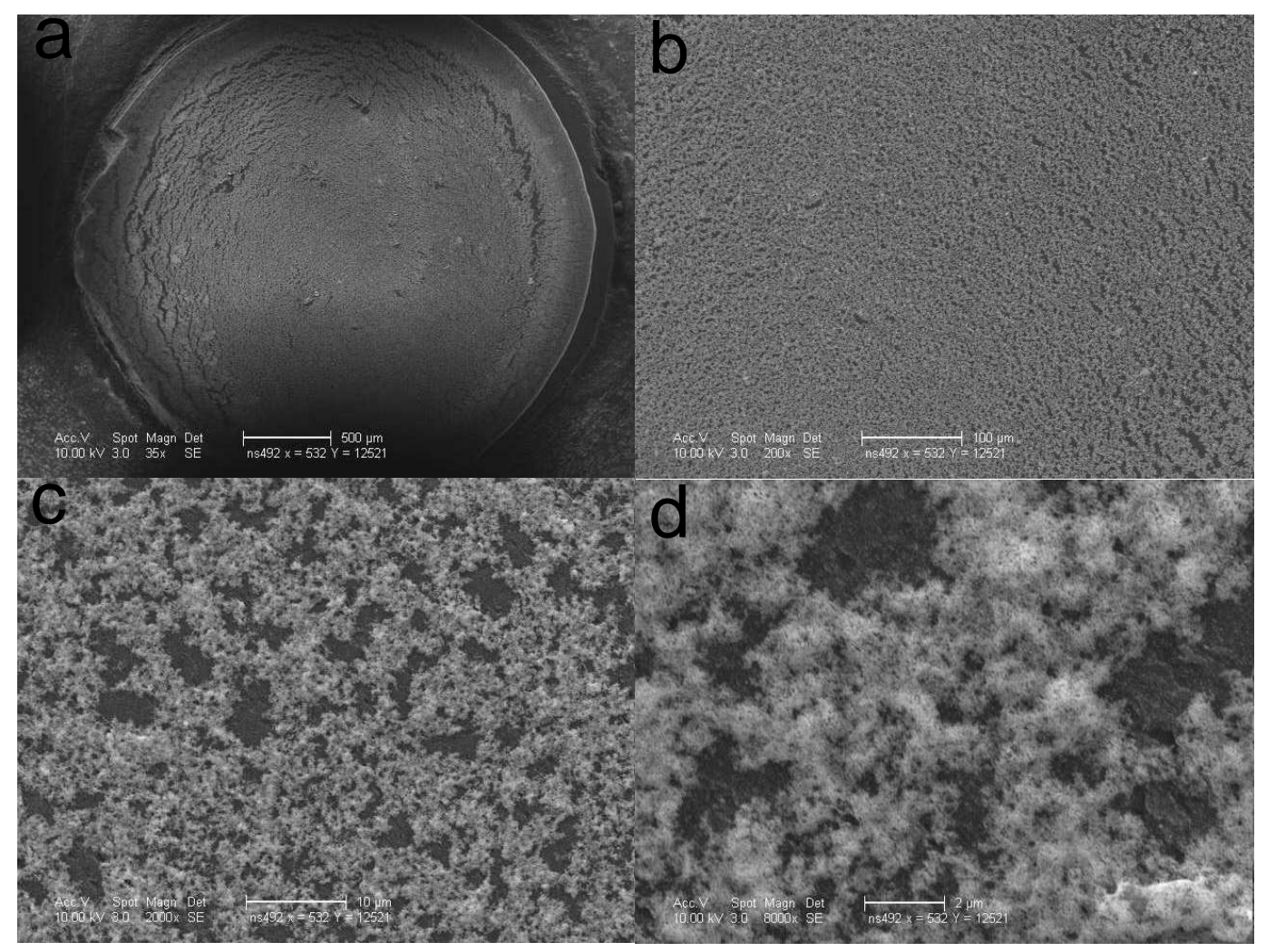

Figure S4 Typical SEM images at different magnification of $\mathrm{Au}_{25} \mathrm{Pt}_{75}$ nanoparticles placed on the glass carbon electrode surface. Pt loading was $20 \mathrm{nmol}$. 


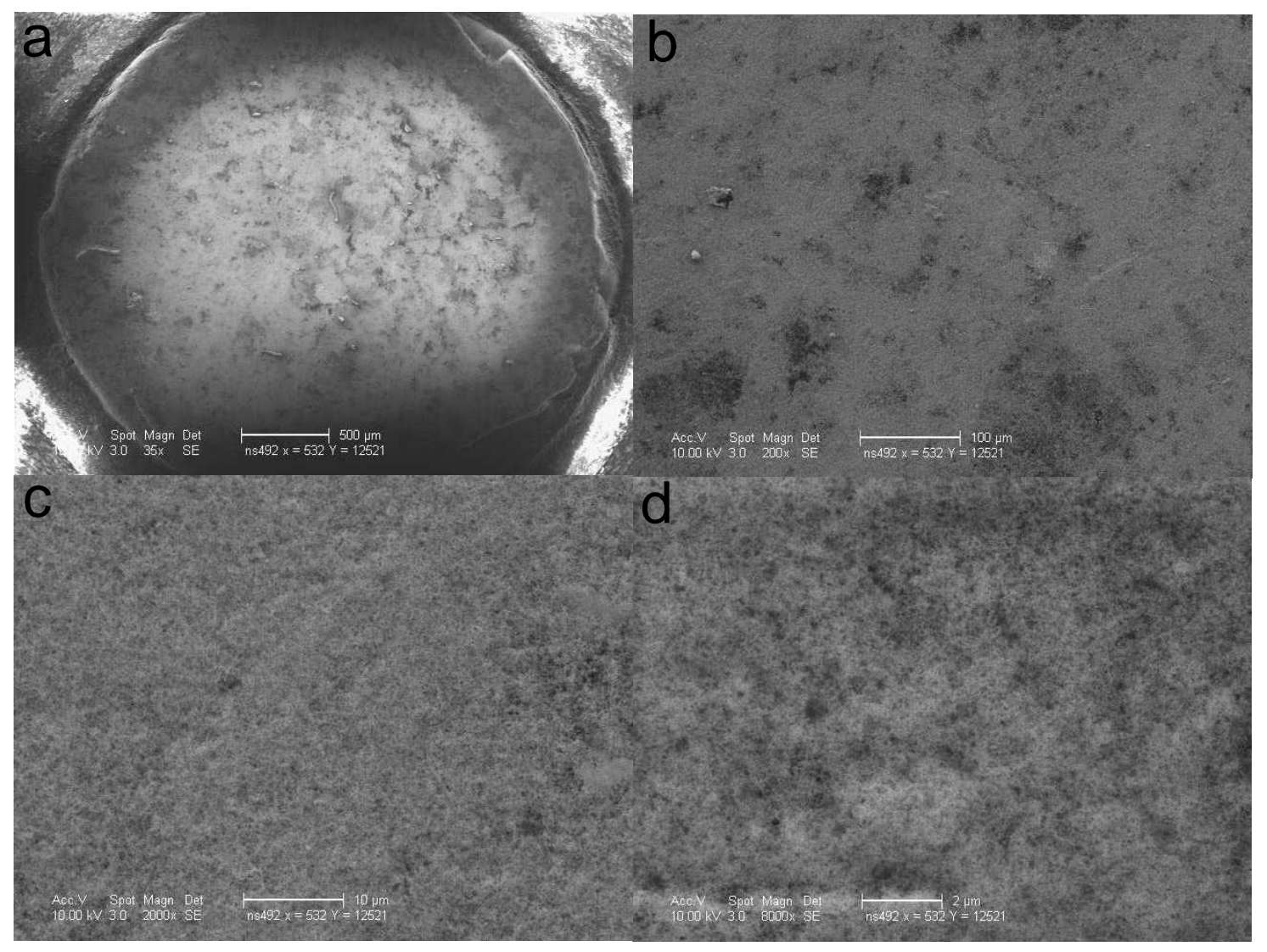

Figure S5 Typical SEM images at different magnification of $\mathrm{Au}_{57} \mathrm{Pt}_{43}$ nanoparticles placed on the glass carbon electrode surface. Pt loading was $20 \mathrm{nmol}$. 